\title{
DEBRIS EXTRUSION FROM SEVERELY CURVED ROOT CANALS AFTER INSTRUMENTATION WITH WAVEONE GOLD OR ONESHAPE SINGLE FILES
}

\author{
Hend Mahmoud Abou El Nasr* and Shaimaa Ismail Gawda***
}

\begin{abstract}
Aim: The aim of this study was to assess the effect of degree of curvature on extrusion of debris from root canals; and to compare the amount of extruded debris after instrumentation with WaveOne Gold reciprocating (WOG; Dentsply Maillefer, Ballaigues, Switzerland) and OneShape rotating (OS; MicroMega, Besançon, France) single file systems.

Materials and methods: Sixty mesiobuccal canals were assigned to 2 equal groups according to the degree of curvature, whether severe $\left(25-40^{\circ}\right)$ or moderate $\left(10-15^{\circ}\right)$ as measured using Schneider method. The canals in each group were further subdivided into 2 subgroups $(n=15)$ according to the instrument used for preparation; WaveOne Gold (WOG) or OneShape (OS) files. The extruded debris was collected in preweighed glass vials. Data were statistically analyzed using One-way ANOVA and Tukey's post-hoc tests.
\end{abstract}

Results: The least amounts of debris were obtained with WaveOne Gold instruments in both curvatures, with no significant difference between them $(\mathrm{P}>0.05)$. Larger amounts of debris occurred with OneShape instruments in severely curved canals; but this difference was of no statistical significance. Statistically significant differences were recorded only when OneShape instruments were used in moderately curved canals.

Conclusions: Debris extrusion occurs independent of the motion or design of the instrument. However, moderate root canal curvatures allowed more extrusion of debris than severe curves. WaveOne Gold results were not affected by the degree of canal curvature; and outperformed OneShape instruments in both types of curves.

KEY WORDS : Debris extrusion, severe canal curvature, OneShape, WaveOne Gold, reciprocation

* Department of Endodontics, Faculty of Oral and Dental Medicine, Cairo University, Egypt 


\section{INTRODUCTION}

The incidence of flare up during root canal treatment ranges between $1.4 \%$ to $16 \%{ }^{(1)}$. One important cause has been the instrumentation process ${ }^{(2,3)}$. During root canal preparation, dentin chips, pulp tissue, and microorganisms may be pushed into the periradicular tissues; potentially causing interappointment flare-up and postoperative pain $^{(4-6)}$.

It has been indicated that although the type of extruded material is not under the control of the operator; its amount can be controlled by selecting the preparation techniques ${ }^{(1)}$, and the design and kinematics of endodontic instruments ${ }^{(7)}$.

It is assumed that the reduction in the number of files decreases the amount of debris extruded; and so the prevalence of apical periodontitis. But, a systematic review concluded that both, full sequence and single file systems generated apical extrusion of debris in vitro and expression of neuropeptides in vivo. It suggested that this inflammatory reaction is not influenced by the number of files but the type of movement and the instrument design ${ }^{(8)}$.

Clinical studies assessing postoperative pain after instrumentation using single files with different kinematics supported this conclusion ${ }^{(9-11)}$. Those were performed on posterior teeth because it is likely that the practitioner will be faced with severely curved roots in clinical practice. Likewise, it was found that mandibular molars had the lowest success rate in primary root canal treatment compared with other tooth types ${ }^{(12)}$.

However, the majority of laboratory studies on debris extrusion used single rooted teeth with relatively straight canals ${ }^{(4)}$ yielding controversial and inconclusive results ${ }^{(5,13,14)}$. So, irrespective of the technique used, anatomical variables such as canal curvature and apical diameter are important factors ${ }^{(4,6)}$.
There is a great tendency among clinicians to use single file systems because they reduce the time of the preparation ${ }^{(15)}$. Furthermore, reciprocation extends the life span of nickel titanium (NiTi) files, improves their resistance to cyclic fatigue ${ }^{(16,17)}$; and, does not reduce their cutting efficiency ${ }^{(5)}$.

WaveOne Gold (Dentsply Maillefer, Ballaigues, Switzerland) is a recent single file reciprocating instrument manufactured using a new proprietary super metal technology termed Gold-wire, producing a superelastic NiTi file ${ }^{(18)}$. It extruded less debris than WaveOne from straight canals of mandibular premolars ${ }^{(19)}$. However, it was not challenged in root canals with severe curvatures ${ }^{(4)}$.

Thus, the aim of the present study was twofold: to assess the effect of the degree of curvature on extrusion of debris from root canals; and to compare between WaveOne Gold reciprocating and OneShape rotating single file systems in terms of debris extrusion from these canals.

\section{MATERIALS AND METHODS}

\section{Sample selection}

Maxillary and mandibular molars with mature apices were collected, cleaned from calculus and debris, and examined under surgical operating microscope (G6, Global Surgical Corp; USA) for defects or resorptions in their mesial roots.

They were placed in full concentration of $\mathrm{NaOCl}$ for one hour to remove soft debris and then stored in sterile saline until use.

Access cavities were prepared in all teeth using diamond burs. The patency in mesiobuccal canals was verified by inserting a size $10 \mathrm{~K}$ file (Dentsply Maillefer) into the root canal until its tip was visible at the apical foramen. The working length was set at $1 \mathrm{~mm}$ shorter of this measurement.

Working lengths were then adjusted to $17 \mathrm{~mm}$ in all the canals to eliminate confounders which might affect the results. 
The mesiobuccal canals with initial apical diameter corresponding to size $15 \mathrm{~K}$-file were assessed for the degree of curvature with Cone beam 3D X-ray system (CBCT) (Scanora 3D, Soredex, Finland). The angle of curvature was measured using OnDemand 3D software according to Schneider method ${ }^{(20)}$.

From this pool, thirty canals with severe curvatures $\left(25-40^{\circ}\right)$ and another thirty canals with moderate curvatures $\left(10-15^{\circ}\right)$ were included in the study. Random assignment to groups:

The 60 mesiobuccal canals were randomly assigned to one of the test instruments as follows:

Group 1: WaveOne Gold used in severe curvatures $(\mathrm{n}=15)$.

Group 2: OneShape used in severe curvatures $(\mathrm{n}=15)$.

Group 3: WaveOne Gold used in moderate curvatures $(\mathrm{n}=15)$.

Group 4: OneShape used in moderate curvatures $(\mathrm{n}=15)$.

\section{Mechanical preparation}

Root canals were irrigated with $3 \mathrm{~mL}$ distilled water after each file. Irrigation was performed in the same manner for all specimens using a $5 \mathrm{~mL}$ disposable plastic syringe with a $28 \mathrm{G}$ needle placed near to the working length without binding. Before instrumentation, PathFile instruments (Dentsply Maillefer) were used in all groups in a rotation of $300 \mathrm{rpm}$ and $0.6 \mathrm{Ncm}$. Each of the test instruments was used to prepare 5 canals, and canal patency was maintained with size $10 \mathrm{~K}$ file.

\section{WaveOne Gold instruments (WOG)}

The canals were prepared with the WOG primary instrument (25/.07) using the X- Smart Plus (Dentsply Maillefer) electric motor that was adjusted for reciprocating motion according to the manufacturer's instructions. The instrument was used in an in and out motion until the working length was reached.

\section{One Shape instruments (OS)}

A OneShape file (MicroMega, Besançon, France) having a size 25 at the tip and a taper of $6 \%$ was used in a pecking motion with rotational speed of $350 \mathrm{rpm}$ and the torque was adjusted to $2 \mathrm{Ncm}$ in the $\mathrm{X}$-Smart Plus electric motor (Dentsply Maillefer). Once the instrument has negotiated to the working length and had rotated freely, instrumentation was considered complete.

All root canals in the 4 groups were instrumented by only one operator, whereas the assessment of extruded debris was performed by a 2 nd examiner who was blinded to the experimental groups.

\section{Collection of debris}

The method used for collection of apically extruded debris was adapted from the original method suggested by Myers and Montgomery in preweighed glass recipients ${ }^{(21)}$.

A $10-\mathrm{mL}$ glass vial was used to collect the debris. The vials were individually preweighed 3 times with a $10^{-4}$-g precision analytic microbalance (ADAM, UK). The mean weight of each vial was recorded as the baseline reading. A rubber dam sheet was used to cover the vial and was attached to it using orthodontic elastic bands (American Orthodontics Elastics, 1/4" Medium, $6.4 \mathrm{~mm}$ ). A hole was then cut in the sheet where the tooth was secured while having its roots freely exposed in the aperture of the vial. A 30-G needle was inserted into the rubber sheet to balance internal and external pressures, allowing debris extrusion. The teeth were instrumented into this assembly.

Once instrumentation was completed, each tooth was separated from the vial, and the debris adhering to the root surface was collected by washing the root with $1 \mathrm{~mL}$ of distilled water into the vial. 
The vials were then placed in a microwave (Samsung, 20L Microwave (ME732K) adjusted to maximum power $(800 \mathrm{~W})$ for 5 minutes, allowing evaporation of the irrigant. Three consecutive weight measurements were taken for each vial, and the mean values were recorded. The weight of the extruded debris was determined by subtracting the weight of the preweighed vials from the final weight of the vials.

\section{Statistical analysis}

Data were explored for normality using Kolmogorov-Smirnov test. One-way ANOVA was used to compare debris extrusion in all tested groups; while Tukey's post-hoc test was used for pair wise comparison. The significance level was set at $\mathrm{P} \leq 0.05$. Statistical analysis was performed with IBM ${ }^{\circledR}$ SPSS $®$ Statistics Version 24 for Windows (SPSS Inc., IBM Corporation, NY, USA).

\section{RESULTS}

The mean and standard deviation values were calculated and tabulated in Table 1. The least amounts of debris were obtained with WaveOne Gold instruments in severe or moderate curvatures, with no significant difference between them $(P>0.05)$. Larger amounts of debris were observed when OneShape instruments were used in severely curved canals; this difference was of no statistical significance.

Statistically significant differences were recorded only when OneShape instruments were used in moderately curved canals.

\section{DISCUSSION}

The primary aim of the present study was to find out whether the degree of root canal curvature affects the amount of debris extruded apically.

Therefore, mesiobuccal canals with severe and moderate curvatures were selected.

The degree of curvature was measured by CBCT using Schneider method ${ }^{(20)}$, and was assessed only in the clinical view because it was found that the greatest curvature was present in the clinical view of mesiobuccal canals of mandibular molars ${ }^{(22)}$. In fact, we had great difficulty finding mesiobuccal canals with moderate curvatures and they mostly belonged to maxillary molars.

The initial apical diameter as well as the working length were standardized for all canals to avoid any variables that could affect the results. Working lengths were determined $1 \mathrm{~mm}$ short of the apex because debris extrusion is significantly reduced at this level ${ }^{(8,21)}$.

The teeth were secured to glass vials and those were masked by the rubber dam sheets to blind the operator regarding the production of debris during instrumentation ${ }^{(4)}$.

All instrumentation procedures were performed by one operator and started by using Pathfile instruments. The necessity to obtain a glide path before file usage is controversial (5); however, it was preferred to establish a glide path as per the manufacturers' recommendations for both systems used in this study.

TABLE (1) Mean and standard deviation values for the debris extrusion (gm) for different groups

\begin{tabular}{|c|c|c|c|c|c|c|c|c|c|}
\hline & \multicolumn{2}{|c|}{ Group 1 } & \multicolumn{2}{c|}{ Group 2 } & \multicolumn{2}{c|}{ Group 3 } & \multicolumn{2}{c|}{ Group 4 } & p-value \\
\cline { 2 - 9 } & Mean & SD & Mean & SD & Mean & SD & Mean & SD \\
\hline Weight $(\mathrm{gm})$ & $0.00157 \mathrm{~b}$ & 0.00078 & $0.00217 \mathrm{~b}$ & 0.00087 & $0.00166 \mathrm{~b}$ & 0.00066 & $0.00289 \mathrm{a}$ & 0.00062 & $0.003 *$ \\
\hline
\end{tabular}


Two single file systems were selected with different kinematics; thus unifying the number of instruments reaching the working length and the preparation protocol.

In order to standardize the final size of the apical preparation, the Primary file was selected for the WaveOne Gold system and the OneShape file was selected for the OneShape system. Both having same tip size (\#25) and matching tapers of $7 \%$ and $6 \%$ respectively.

Because debris as well as irrigants may be extruded apically, the extruded liquid needs to be evaporated by storage in a desiccator ${ }^{(4)}$. The microwave used in this study was a fast and reliable method for drying the glass containers. Distilled water was the irrigant used because during the drying process, crystals of $\mathrm{NaOCl}$ are likely to remain which might adversely affect the reliability of the experimental methodology ${ }^{(4)}$.

To avoid any bias during weight measurements, a different investigator - who was blinded to the test groups - was responsible for weighing the vials in triplicates before and after instrumentation, and to record the mean weight values.

The results showed that the degree of curvature did not affect the amount of debris extruded when WaveOne Gold instrumented the canals; although the recorded amounts were slightly higher in moderate curves. Conversely, when OneShape rotating instruments were used, significantly more debris were extruded from moderately curved canals.

It is possible that the small curve of the canal facilitated the movement of the instruments and favoured pushing the debris in apical direction. While instrumenting severely curved canals may have caused the debris to get smeared to the canal walls; or clogged within the flutes of the instrument itself.

This emphasizes the importance of instrument design in providing enough space for the clearance of debris from root canals. Elements of the file design such as flute depth and cross section tend to direct debris toward the canal orifice and force the material outwards coronally ${ }^{(5,7,13)}$.

OneShape file has variable cross section, with apical $2 \mathrm{~mm}$ presenting with 3 cutting edges, followed by a transition zone in the next $7.5 \mathrm{~mm}$ where the cross section changes from three cutting edges to two. It has positive rake angle, progressive pitch, and constant taper of $6 \%$. All these features may contribute to the increased production of debris. However, the 2-cutting-edge zone in the coronal portion combined with the variable helix angle provide increased chip space and upward debris removal ${ }^{(6,10)}$.

On the other hand, WaveOne Gold has offset parallelogram-shaped cross section where only one cutting edge is in contact with the canal wall, limiting the engagement zone. It has a progressively decreasing percentage taper from D4-D16 which preserves dentin ${ }^{(18)}$.

Indeed, the answer to the 2nd question of this study comparing both instruments, was that OneShape produced more debris than WaveOne Gold in both curvatures.

These results are in line with those of Çapar and Arslan who found that files with rectangular cross section produced less debris extrusion than those with triangular one ${ }^{(23)}$; and supported by Arslan et al. who found that Reciproc instruments extruded less debris when used in reciprocation than in continuous rotation ${ }^{24)}$. However, they are not corroborating those of Burklein and Schäfer who hypothesized that rotary files act like a screw conveyor that tends to pack dentinal debris into flutes and send it in a cervical direction ${ }^{(15,25)}$.

The findings in the present study question the cutting efficiency as well as the cleaning ability of the 2 instruments used. Unfortunately, the current literature has no answers for these questions. Nonetheless, each file instrumented only 5 canals to approximate the instrumentation of one molar; which should not affect the cutting efficiency. 
While more debris extruded from moderate curves in the present study, evidence shows that the majority of postoperative pain is related to molar teeth, especially mandibular ones ${ }^{(12)}$. This confirms the multifactorial nature of postendodontic pain. It is related to host, operator, and also instrument factors such as cross section, speed, and type of movement ${ }^{(8,13)}$.

\section{CONCLUSION}

Under the conditions of this study, it was concluded that debris extrusion is an inevitable consequence of root canal instrumentation. Moderate canal curvatures are more inviting to extrusion of debris than severe curves. Moreover, WaveOne Gold results were not affected by the degree of canal curvature; and outperformed OneShape instruments in both types of curves.

\section{ACKNOWLEDGEMENT}

We affirm that we have no financial affiliation or involvement with any commercial organization with direct financial interest in the subject or materials discussed in this manuscript, nor have any such arrangements existed in the past three years. The authors deny any conflicts of interest.

\section{REFERENCES}

1. Siqueira JF Jr. Microbial causes of endodontic flare-ups. Int Endod J 2003;36:453-463.

2. Cunningham CJ, Mullaney TP. Pain control in endodontics. Dent Clin North Am 1992;36:393-408.

3. Seltzer S, Naidorf IJ. Flare-ups in endodontics: I. Etiological factors. 1985. J Endod 2004;30:476-481.

4. Tanalp J, Güngör T. Apical extrusion of debris: a literature review of an inherent occurrence during root canal treatment. Int Endod J 2014;47:211-221.

5. Plotino G, Ahmed HM, Grande NM, Cohen S, Bukiet F. Current assessment of reciprocation in endodontic preparation: A comprehensive review - Part II: properties and effectiveness. J Endod 2015;41:1939-1950.
6. Mittal R, Singla MG, Garg A, Dhawan A. A comparison of apical bacterial extrusion in manual, ProTaper rotary, and One Shape rotary instrumentation techniques. J Endod 2015;41:2040-2044.

7. Borges ÁH, Pereira TM, Porto AN, de Araújo Estrela CR, Miranda Pedro FL, Aranha AM, Guedes OA. The influence of cervical preflaring on the amount of apically extruded debris after root canal preparation using different instrumentation systems. J Endod 2016;42:465-469.

8. Caviedes-Bucheli J, Castellanos F, Vasquez N, Ulate E, Munoz HR. The influence of two reciprocating single-file and two rotary-file systems on the apical extrusion of debris and its biological relationship with symptomatic apical periodontitis. A systematic review and meta-analysis. Int Endod J 2016;49:255-270.

9. Gambarini G, Testarelli L, De Luca M, Milana V, Plotino G, Grande NM, Rubini AG, Al Sudani D, Sannino G. The influence of three different instrumentation techniques on the incidence of postoperative pain after endodontic treatment. Ann Stomatol (Roma) 2013;4:152-155.

10. Neelakantan P, Sharma S. Pain after single-visit root canal treatment with two single-file systems based on different kinematics--a prospective randomized multicenter clinical study. Clin Oral Investig 2015;19:2211-2217.

11. Mollashahi NF, Saberi EA, Havaei SR, Sabeti M. Comparison of postoperative pain after root canal preparation with two reciprocating and rotary single-file systems: A randomized clinical trial. Iran Endod J 2017; 12:15-19.

12. Ng YL, Mann V, Rahbaran S, Lewsey J, Gulabivala K. Outcome of primary root canal treatment: systematic review of the literature - Part 2. Influence of clinical factors. Int Endod J 2008;4:6-31.

13. Nayak G, Singh I, Shetty S, Dahiya S. Evaluation of apical extrusion of debris and irrigant using two new reciprocating and one rotation single file systems. J Dent (Tehran University) 2014;11:302-309.

14. Bürklein S, Benten S, Schäfer E. Quantitative evaluation of apically extruded debris with different single-file systems: Reciproc, F360 and OneShape versus Mtwo. Int Endod J 2014;47:405-409.

15. Bürklein S, Schäfer E. Apically extruded debris with reciprocating single-file and full-sequence rotary instrumentation systems. J Endod 2012;38:850-852. 
16. Gambarini G, Gergi R, Naaman A, Osta N, Al Sudani D. Cyclic fatigue analysis of twisted file rotary NiTi instruments used in reciprocating motion. Int Endod $\mathrm{J}$ 2012;45:802-806.

17. Shin CS, Huang YH, Chi CW, Lin CP. Fatigue life enhancement of NiTi rotary endodontic instruments by progressive reciprocating operation. Int Endod $\mathrm{J}$ 2014;47:882-888.

18. Dentsply Tulsa Dental Specialties. Wave One Gold. https:// www.dentsply.com/content/dam/dentsply/pim/manufacturer/Endodontic s/Obturation/Gut t a_ P e r cha_Points/ WaveOne_Gold_Gutta_Percha_Points/W1G_Brochure_ EN.pdf.

19. Karataş E, Ersoy İ, Gündüz HA, Uygun AD, Kol E, Çakıcı F. Influence of instruments used in root canal preparation on amount of apically extruded debris. Artif Organs 2016;40:774-777.

20. Schneider SW. A comparison of canal preparations in straight and curved root canals. Oral Surg Oral Med Oral Pathol 1971;32:271-275.
21. Myers GI, Montgomery S. a comparison of weight of debris extruded apically by conventional filing and Canal Master techniques. J Endod 1991;17:275- 279.

22. Slowey RR. Root canal anatomy: Road map to successful endodontic. Dental Clin North Am 1979;23:555-573.

23. Çapar ID, Arslan H. A review of instrumentation kinematics of engine-driven nickel-titanium instruments. Int Endod J 2016;49:119-135.

24. Arslan H, Doğanay E, Alsancak M, Çapar ID, Karataş E, Gündüz HA. Comparison of apically extruded debris after root canal instrumentation using Reciproc(®) instruments with various kinematics. Int Endod J 2016;49:307-310.

25. Tanalp J, Kaptan F, Sert S, Kayahan B, Bayirl G. Quantitative evaluation of the amount of apically extruded debris using 3 different rotary instrumentation systems. Oral Surg Oral Med Oral Pathol Oral Radiol Endod 2006;101:250-257. 